\title{
Lancemaside A, a major triterpene saponin of Codonopsis lanceolata enhances regulation of nitric oxide synthesis via eNOS activation
}

Young Seok Lee ${ }^{1+}$, HeeEun Kim² ${ }^{2+}$, Jinhye Kim', Geun Hee Seol ${ }^{3^{*}}$ and Kwang-Won Lee ${ }^{1 *}$ (D)

\begin{abstract}
Background: Many studies on the effect of saponin-rich Codonopsis lanceolata as a bioactive source for improving physical health have been performed. C. lanceolata contains triterpenoid saponins, including lancemasides. These saponins are known to be particularly involved in the regulation of blood pressure or hypertension. This study investigated whether lancemaside $A(L A)$, a major triterpenoid saponin from C. lanceolata, regulates nitric oxide (NO) production via the activation of endothelial NO synthase (eNOS) in human umbilical vein endothelial cells.

Methods: Upon separation with petroleum ether, ethyl acetate, and $n$-butanol, LA was found to be abundant in the $n$-butanol-soluble portion. For further purification of LA, HPLC was performed to collect fraction, and LA was identified using analysis of LC/MSMS and ${ }^{13} \mathrm{C}-\mathrm{NMR}$ values. In in vitro, the effects of LA on NO release mechanism in HUVECs were investigated by Griess assay, quantitative real-time reverse-transcription PCR, and Western blotting.

Results: Our results showed that NO production was efficiently improved by treatment with LA in a dosedependent manner. In addition, the LA treatment resulted in extensive recovery of the NO production suppressed by the eNOS inhibitor, L-NAME, compared with that in the control group. Additionally, the level of eNOS mRNA was increased by this treatment in a dose-dependent manner. These results suggested that LA is an inducer of NO synthesis via eNOS mRNA expression. Also, the study indicated that LA is involved in activating the PI3K/Akt/eNOS signaling pathway.
\end{abstract}

Conclusion: These results suggested that LA is an inducer of NO synthesis via eNOS mRNA expression. Also, the study indicated that LA is involved in activating the PI3K/Akt/eNOS signaling pathway. These findings suggest the value of using LA as a component of functional foods and natural pharmaceuticals.

Keywords: Codonopsis lanceolata, Lancemaside A, Nitric oxide, Endothelial NO synthase, PI3K/Akt/eNOS signaling pathway, Hypertension

\footnotetext{
* Correspondence: ghseol@korea.ac.kr; kwangwon@korea.ac.kr

${ }^{\dagger}$ Young Seok Lee and Hee Eun Kim contributed equally to this work.

${ }^{3}$ Department of Basic Nursing Science, College of Nursing, Korea University, Seoul 02841, South Korea

'Department of Biotechnology, College of Life Science and Biotechnology, Korea University, 212 CJ Food Safety Hall, Sungbuk-Gu, Anam-Ro 145, Seoul 02841, South Korea

Full list of author information is available at the end of the article
}

(c) The Author(s). 2019 Open Access This article is distributed under the terms of the Creative Commons Attribution 4.0 International License (http://creativecommons.org/licenses/by/4.0/), which permits unrestricted use, distribution, and reproduction in any medium, provided you give appropriate credit to the original author(s) and the source, provide a link to the Creative Commons license, and indicate if changes were made. The Creative Commons Public Domain Dedication waiver (http://creativecommons.org/publicdomain/zero/1.0/) applies to the data made available in this article, unless otherwise stated. 


\section{Background}

Codonopsis lanceolata is a natural ingredient, which is edible raw or cooked, and has also been used as a traditional medicine in East Asia for the treatment of inflammatory disorders such as cough, bronchial asthma, tonsillitis, and pharyngitis [1, 2]. C. lanceolata extract has also been reported to protect the liver damage $[3,4]$, counter obesity [5], induce memory development [6, 7], and inhibit tumors [8]. C. lanceolata contains various phytochemical components, including many different triterpenoid saponins such as lancemaside $\mathrm{A}-\mathrm{C}, \mathrm{E}$, and $\mathrm{G}$, foetidissimoside $\mathrm{A}$, and aster saponin $\mathrm{Hb}$ [9]. $\mathrm{Al}-$ though the effects of other saponin compounds from $A s$ tragalus corniculatus [10], Panax notoginseng [11], and soybean [12] are widely known, the effects of saponin-rich $C$. lanceolata remain to be fully explained and evaluated in terms of other disease applications.

Recently, we reported that C. lanceolata extract is effective in preventing hypertension and reducing systolic blood pressure (SBP) in rats [13]. The treatment of hypertentive rats with both $200 \mathrm{mg}$ and $400 \mathrm{mg}$ of $C$. lanceolata extract per $\mathrm{kg}$ body weight significantly reduced SBP compared with the hypertentive vehicle, whereas the plant extract did not decrease SBP in normotensive rats. We hypothesized that lancemaside A (LA) occurring in this plant contributes to these hypotensive effects, because LA is a major triterpenoid saponin contained in C. lanceolata.

Lancemaside $\mathrm{A}$ is reported to enhance anti-inflammatory function by blocking IKK/NF-kB activation on RAW 264.7 and U937 cells [14] and potently ameliorates colitis via TLR-linked NF-kB activation in mice [15]. In addition, LA was reported to suppress microglial activation, which plays an important role in neurodegenerative diseases via regulation of the JNK signaling pathway [16]. Moreover, LA and its metabolite, echinocystic acid, improved scopolamine-induced memory and learning deficits in mice by inhibiting acetylcholinesterase activity and inducing brain-derived neurotrophic factor and phosphorylated cAMP response element binding protein (p-CREB) expression.

Endothelial nitric oxide synthase (eNOS), which synthesizes a nanomolar amount of nitric oxide (NO), is an isozyme of NOS; other NOS isozymes include neuronal NOS (nNOS), inducible NOS (iNOS), and bacterial NOS (bNOS) [17]. eNOS phosphorylation is mediated through PPAR- $\gamma$-eNOS, oxidative stress, and Rho-kinase pathway [18], angiopoietinrelated growth factor [19], VEGF-mediated focal adhesion kinase (FAK) phosphorylation in hypoxia [20], or the phosphatidylinositol-3-kinase (PI3K)/protein kinase B (PKB, Akt) signaling pathway to regulate $\mathrm{NO}$ synthesis [21]. NO, which plays an important role in modulating blood pressure, is formed from L-arginine by eNOS phosphorylation [22]. Synthesized NO stimulates soluble guanylyl cyclase (sGC), which is a receptor for $\mathrm{NO}$ in smooth muscle cells (SMC), thereby converting guanosine triphosphate (GTP) to cyclic guanosine monophosphate (cGMP) [23]. Activation of sGC leads to vascular relaxation via NO-cGMP signaling [24]. These endothelial functional effects of saponin from ginseng, such as ginsenoside-Rg1, on NO production via the PI3K/ Akt/eNOS signaling pathway in HUVECs are well known $[25,26]$. However, no study has yet reported the effects of LA on NO synthesis through eNOS phosphorylation.

To bridge this research gap, LA was isolated from the ethanol extract of C. lanceolata and identified by several instrumental approaches. In this study, efforts were then made to evaluate its effect on $\mathrm{NO}$ production via eNOS activation.

\section{Methods}

\section{Chemicals and materials}

Materials were purchased respectively as follows: EGM-2 medium kit from Lonza Cambrex (Nottingham, UK), enhanced chemiluminescence (ECL) reagent from AbClon (Seoul, South Korea), Griess reagent from Promega Co. (WI, USA), LeGene Premium Express 1st Strand cDNA Synthesis System from LeGene Biosciences (CA, USA), polyvinylidene fluoride (PVDF) membranes from Millipore (MA, USA), pyridine- $d 5$ from Cambridge Isotope Laboratories Inc. (MA, USA), RNAiso PLUS from TAKARA Korea Biomedical Co. (Seoul, South Korea), thin-layer chromatography (TLC) silica gel $60 \mathrm{~F}_{254}$ from Merck (Darmstadt, Germany), and TOPreal ${ }^{\mathrm{Tm}}$ qPCR $2 \times$ PreMIX SYBR green from Enzynomics (Seoul, South Korea). N(G)-nitro-L-arginine methyl ester (L-NAME), fetal bovine serum (FBS), and silica gel resin were purchased from Sigma-Aldrich (MO, USA). All other chemicals were of ultra-pure grade. The primary antibodies (eNOS, phospho-eNOS Ser ${ }^{1177}$, Akt, phospho-Akt Thr ${ }^{308}$, and GAPDH) and horseradish peroxidase (HRP)-conjugated secondary antibodies (anti-rabbit and anti-mouse) were obtained from Merckmillipore (CA, USA). All other chemicals were of ultra-pure grade.

\section{Separation of LA from C. lanceolata Plant materials}

The edible rhizomes of $C$. lanceolata were identified and obtained from PANAX KOREA Co., Ltd. (Gangwon-do, South Korea). The voucher specimen (KUH-359) was deposited at Korea University Herbarium. The fresh rhizomes were washed and sliced, and then the sliced rhizomes were immediately dried in a freeze-dryer. The dried $C$. lanceolata was finely ground in a mortar and kept refrigerated at $4{ }^{\circ} \mathrm{C}$.

Extraction, isolation, and isolation of LA from C. Ianceolata The parched rhizomes of $C$. lanceolata $(100 \mathrm{~g})$ were extracted with $55 \%$ ethanol at $60{ }^{\circ} \mathrm{C}$ for $4.5 \mathrm{~h}$ using a reflux condenser and then cooled. The undissolved remains were 
filtrated using Whatman qualitative filter paper 2 (Whatman Inc., Clifton, NJ, USA). The filtrate was concentrated using a rotary vacuum evaporator (N-1000S; EYELA, Tokyo, Japan) and then lyophilized to yield $46.31 \mathrm{~g}$ of powder. Our group reported that LC/MS analysis of the compounds from this ethanol extract of $C$. lanceolata contain lancemaside A, B, C, E, and G, foetidissimoside A, and aster saponin $\mathrm{Hb}$ (Han et al. 2018). For further fractionation of the dried C. lanceolata extract, the extract was resuspended in $\mathrm{H}_{2} \mathrm{O}$ and then successively extracted with petroleum ether, ethyl acetate, and $n$-butanol. The $n$-butanol-soluble portion $(7.79 \mathrm{~g})$ was applied to silica gel open column chromatography and eluted with a gradient of increasing methanol in dichloromethane (DCM). Finally, the active fraction of DCM and methanol $(60: 40, \mathrm{v} / \mathrm{v})(0.49 \mathrm{~g})$ was further separated using the Agilent Technologies 1200 Series HPLC system. The separation was performed using a YMC-Triart $\mathrm{C}_{18}$ column $(5 \mu \mathrm{m}, 4.6 \times 250 \mathrm{~mm})$. HPLC separation was performed with a flow rate of $1 \mathrm{~mL} / \mathrm{min}$ (injection volume, $20 \mu \mathrm{L}$ ), with a linear gradient of solvent mixtures of $0.05 \%$ trifluoroacetic acid (TFA) in $\mathrm{H}_{2} \mathrm{O}$ (solvent $\mathrm{A}$ ) and $\mathrm{CH}_{3} \mathrm{CN}$ (acetonitrile, $\mathrm{ACN}$ ) (solvent B) increasing $\mathrm{ACN}$ to $100 \%$ for $60 \mathrm{~min}$. Fractions were collected by a fraction collector (Model 2110; Bio-Rad, USA) at 1-min intervals. The eluted fraction was analyzed using TLC, and LA was isolated ( $0.22 \mathrm{~g}$ ) (Additional file 1: Figure S1).

\section{Thin-layer chromatography}

To select the active fractions that contain LA during the isolation and purification processes, TLC was used. Each HPLC fraction was loaded $(100 \mu \mathrm{g} / \mathrm{lane})$ on a TLC plate coated with silica gel (TLC silica gel $60 \mathrm{~F}_{254}$; Merck, Darmstadt, Germany). The plate was introduced into a saturated TLC chamber consisting of a mobile phase (chloroform-methanol-water 65:35:10, v/v/v) for $30 \mathrm{~min}$ at room temperature. Color formation was performed by $10 \%$ sulfuric acid, followed by heating to $110{ }^{\circ} \mathrm{C}$ on a hot plate.

\section{Liquid chromatography-tandem mass spectrometry analysis (LC-MS/MS)}

Stock samples $(1 \mathrm{mg} / \mathrm{mL})$ of LA for LC-MS/MS were prepared by dissolving $20 \mu \mathrm{g} / \mathrm{mL}$ LA in $50 \%$ methanol $(\mathrm{MeOH})$. The LC-MS/MS analysis was performed by coupling a Nexera X2 HPLC system (Shimadzu, Kyoto, Japan) and an LCMS-8050 mass spectrometer (Shimadzu, Kyoto, Japan) as an electrospray ionization (ESI) source. The mass spectrometric conditions and the optimized multiple reaction monitoring parameters are shown in Additional file 2: Table S1.

\section{${ }^{13} \mathrm{C}$-nuclear magnetic resonance (NMR) analysis}

An NMR experiment was performed to determine the ${ }^{13} \mathrm{C}-\mathrm{NMR}$ spectral patterns of LA in pyridine- $d_{5}(15 \mathrm{mg} /$ $\mathrm{mL})$. Specifically, the analysis was conducted using a liquid-phase cryoporometry NMR system (Avance-600; Bruker, Germany) operating at $600 \mathrm{MHz}$. To compare the observed ${ }^{13} \mathrm{C}$-NMR spectrum of LA, ${ }^{13} \mathrm{C}-\mathrm{NMR}$ data were obtained from the literature [27-29]. The chemical shifts are shown as $\delta$-values (ppm).

\section{Cell culture}

HUVECs were obtained from Lonza Cambrex (Seoul, South Korea) and cultured in endothelial growth medium-2 (EGM-2) supplemented with 2\% FBS under the condition of a humidified atmosphere at $37^{\circ} \mathrm{C}$ with $5 \% \mathrm{CO}_{2}$. Cells from the third to the sixth passage in an active condition were used in this experiment. The cells were treated with various concentrations of LA diluted in EGM-2 $(0.5,1,5,10$, and $15 \mu \mathrm{M})$. For an inhibitor assay with eNOS, HUVECs were treated with an eNOS-specific inhibitor, L-NAME $(25 \mu \mathrm{M})$ for $24 \mathrm{~h}$ before the treatment of LA.

\section{Measurement of NO production}

The HUVECs were cultured on 6-well plates at cell density of $5 \times 10^{5}$ cells/well. To evaluate NO production, the HUVEC cells were treated with LA $(0.5,1,5,10$, and $15 \mu \mathrm{M})$ for $24 \mathrm{~h}$ and an eNOS-specific inhibitor, L-NAME $(25 \mu \mathrm{M})$ for $24 \mathrm{~h}$ before the treatment of LA $(15 \mu \mathrm{M})$ for $24 \mathrm{~h}$, following the medium was collected to measure the amount of NO released by the cells using the Griess assay. The supernatant medium $(100 \mu \mathrm{L})$ in a 96-well plate was mixed with an equal volume of Griess reagent ( $1 \%$ sulfanilamide in $5 \% \quad \mathrm{H}_{3} \mathrm{PO}_{4}$ and $0.1 \%$ $\mathrm{N}$-[1-naphthyl]-ethylenediamine dihydrochloride) and incubated for $10 \mathrm{~min}$. Subsequently, OD was measured spectrophotometrically at $540 \mathrm{~nm}$ using a multi-plate spectrometer.

\section{Quantitative real-time reverse-transcription PCR}

mRNA expression was measured by quantitative real-time reverse-transcription polymerase chain reaction (qRT-PCR). Total RNA isolation, cDNA synthesis, and mRNA expression were performed using RNAiso PLUS (TAKARA Korea Biomedical Co., Seoul, South Korea), LeGene Premium Express 1st Strand cDNA Synthesis System (LeGene Biosciences, CA, USA), and TOPreal $^{\mathrm{Tm}}$ qPCR 2X PreMIX SYBR Green (Enzynomics, Seoul, South Korea), respectively following the manufacturer's instructions. The cycle conditions of an iQ5 thermal cycler (Bio-Rad, CA, USA) were as follows: $3 \mathrm{~min}$ at $95^{\circ} \mathrm{C}$, followed by 30 cycles of incubation at $95^{\circ} \mathrm{C}$ for 3 $\mathrm{s}, 61^{\circ} \mathrm{C}$ for $50 \mathrm{~s}$, and $72^{\circ} \mathrm{C}$ for $1 \mathrm{~min}$. The level of eNOS mRNA expression was normalized to the corresponding value for GAPDH mRNA expression. The sequences of eNOS and GAPDH primers for qRT-PCR analysis were "GGA CGGAGCTGGCTGC" and "GCGTATGCGGC 
TTGTCAC", and these primers accession number in Entrez Nucleotide database is AF400594.

\section{Western blotting assay}

For elucidation of the effect of LA on the phosphorylation of eNOS, HUVECs were treated with LA $(15 \mu \mathrm{M})$ for 20 min and L-LAME $(25 \mu \mathrm{M})$ for $24 \mathrm{~h}$. In addition, for investigation of the function of LA in activation of the Pi3K/ Akt/eNOS signaling pathway, HUVEC were treated with LA and L-LAME for $20 \mathrm{~min}$ and co-incubated with or without a PI3K inhibitor, LY294002 $(25 \mu \mathrm{M})$, and an Akt phosphorylation inhibitor, A6730 $(5 \mu \mathrm{M})$, for $15 \mathrm{~h}$. After the cells had been subjected to different treatments, all cells were rinsed twice with ice-cold phosphate-buffered saline (pH 7.2) and lysed at $4{ }^{\circ} \mathrm{C}$ in RIPA lysis buffer containing proteases (1:1000) and phosphatase inhibitors $(1: 100)$. After the cell lysates had been centrifuged at $13,000 \mathrm{rpm}$ for $20 \mathrm{~min}$ at $4{ }^{\circ} \mathrm{C}$, the supernatant was used as the cellular protein sample. The protein sample $(20 \mu \mathrm{g} /$ lane) was separated by electrophoresing in $7.5 \%$ gel and transferred onto PVDF membrane sheets. The sheets were blocked with $5 \%$ nonfat dry skim milk or bovine serum albumin in TBST [20 mM Tris- $\mathrm{HCl}$ (pH 7.4), $500 \mathrm{mM}$ $\mathrm{NaCl}$, and $0.1 \%$ Tween-20] at room temperature for $1 \mathrm{~h}$. Then, the sheets were bound with specific primary antibodies at $4{ }^{\circ} \mathrm{C}$ overnight, targeting eNOS, phospho-eNOS $\mathrm{Ser}^{1177}$, phospho-Akt $\mathrm{Thr}^{308}$ (dilution 1:1000), Akt (dilution 1:1500), and GAPDH (dilution 1:2000). After rinsing five times with TBST for $30 \mathrm{~min}$, the sheets were probed with HRP-conjugated secondary antibodies (dilutions: anti-rabbit, 1:2000; anti-mouse, 1:4000) at room temperature for $45 \mathrm{~min}$ and rinsed five times with TBST for $30 \mathrm{~min}$. The immunoreactive protein-antibody complexes were visualized using an ECL reagent and scanned by a luminescence image analyzer (LAS-4000; Fuji Film, Tokyo, Japan). The bands were normalized to the GAPDH levels using Image $J$ software (National Institutes of Health, MD, USA).

\section{Statistical analysis}

All results are expressed as mean \pm standard deviation of three independent experiments conducted in triplicate. Different letters indicate significant differences at ${ }^{*} P<$ 0.05 , as determined by Duncan's multiple-range test. All statistical analyses were performed using SAS version 9.4 (SAS Institute, NC, USA).

\section{Results}

\section{Isolation and detection of LA from C. lanceolata}

In previous reports on the separation of lancemaside A, C. lanceolata was extracted with methanol to separate the material $[14,30]$. After their continuous extraction with organic solvents, yields of lancemaside A were 0.11 and $0.13 \%$. In this study, we sought to extract $C$. lanceolata with an environmentally friendly solvent, ethanol and to report in detail on isolation and identification of lancemaside A for increasing the yield of compared with that from previous methods.

Analysis of the eluted fraction was performed using TLC (Additional file 1: Figure S1a). After TLC plates spotted with the fraction were developed in a developing solvent mixture of chloroform $/ \mathrm{MeOH} / \mathrm{H}_{2} \mathrm{O}$ (65:35:10) and dried, the plates containing LA were effectively detected as dark-brown spot, after spraying with $10 \%$ sulfuric acid. Upon separation with petroleum ether, ethyl acetate, and $n$-butanol, LA was found to be abundant in the $n$-butanol-soluble portion (top panel of Additional file 1: Figure S1b). Next, the portion was fractionated into 11 fractions (open column fractions 1-11) by silica gel open column chromatography using a DCM-methanol solvent gradient. As shown in the middle panel of Additional file 1: Figure S1b, LA was mainly identified in open column fraction \#5 (DCM-methanol 60:40, v/v). For further purification of LA, HPLC was performed to collect fractions in 1-min intervals for $60 \mathrm{~min}$ (HPLC fractions 1-60). The bottom panel of Additional file 1: Figure S1b shows that purified LA was obtained from HPLC fraction. The yield of lancemaside A was $0.22 \%$.

\section{Identification of LA from C. lanceolata}

LA ( $R_{t}$ of approximately $3.11 \mathrm{~min}$ ) in ESI-MS with negative-ion mode gave a deprotonated molecule ([M-H] $]^{-}$precursor ion) at $m / z 1189.6$, with the structure of the compound indicating a molecular weight of 1190.6 and the formula $\mathrm{C}_{57} \mathrm{H}_{90} \mathrm{O}_{26}$ (Fig. 1a, top panel of Fig. 1b). The molecular ion $[\mathrm{M}-\mathrm{H}]^{-}$produced three peaks of product ions at $m / z 469.2,585.3$, and 647.5 in MS/MS (bottom panel of Fig. 1b). Among these ion peaks, the major fragmentation peak of LA was at $\mathrm{m} / \mathrm{z}$ 647.5, which was identified as LA [31]. In the MS/MS spectrum of the $[\mathrm{M}-\mathrm{H}]^{-}$ion at $\mathrm{m} / \mathrm{z} 1189.6$, the $\mathrm{m} / \mathrm{z}$ 647.5 ion $\left([\mathrm{M}-\mathrm{H}]^{-}\right)$was produced by the neutral loss of a tetrasaccharide unit (arabinose, rhamnose, and two xyloses) [32]. For analysis of the correlation of the ${ }^{13} \mathrm{C}$-NMR values $(\delta$, ppm) of LA (Fig. $1 \mathrm{c})$, the ${ }^{13} \mathrm{C}$-NMR data of LA were obtained from the literature [27, 31, 33]. To validate the ${ }^{13} \mathrm{C}-\mathrm{NMR}$ data of LA, the chemical shifts of LA were observed and compared with the literature data.

\section{Effects of LA on NO synthesis}

Compared with that in the control group, treatment with various concentrations of LA significantly increased NO production in a dose-dependent manner except the lowest LA level $(0.5 \mu \mathrm{M})$ showing a NO's releasing inferior to the control group (Fig. 2a). As shown in Fig. 2b, treatment of HUVECs with LA significantly increased eNOS mRNA expression in a dose-dependent manner. 


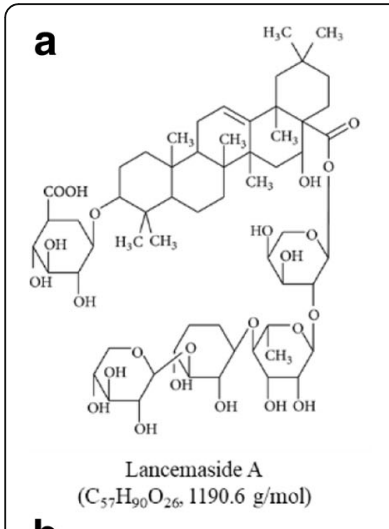

b
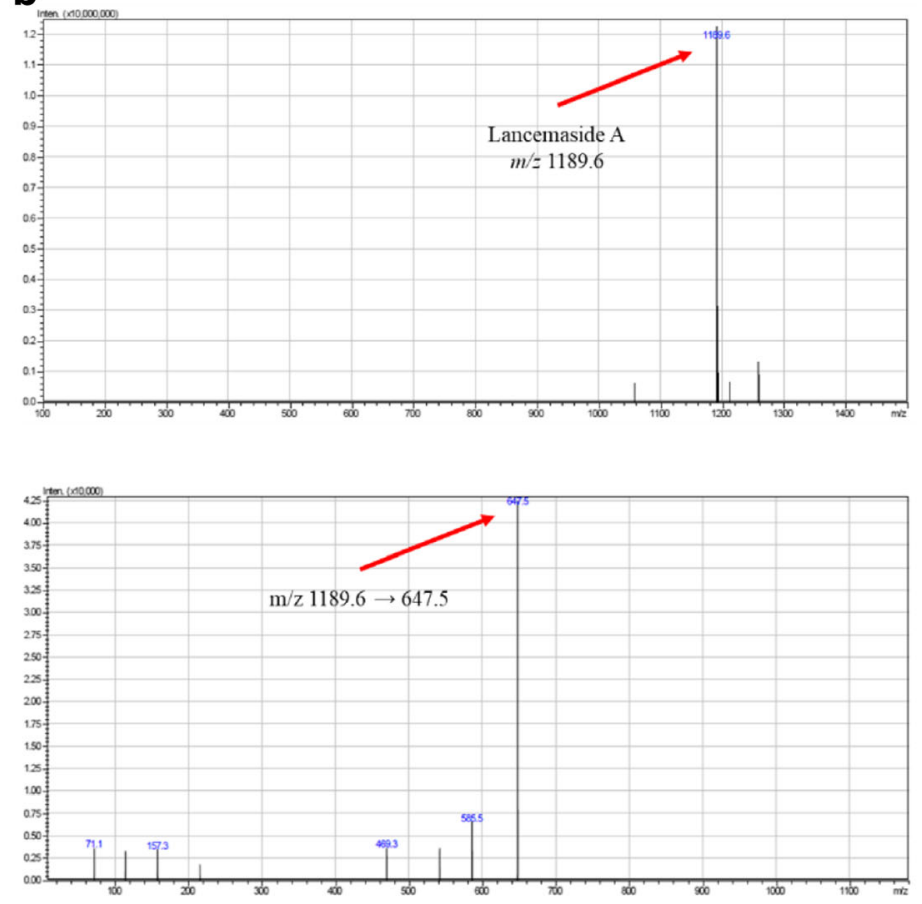

C

\begin{tabular}{|c|c|c|c|}
\hline \multirow[b]{2}{*}{ Carbon } & \multicolumn{3}{|c|}{ Lancemaside $\mathbf{A}$} \\
\hline & $\begin{array}{c}{ }^{13} \mathrm{C}-\mathrm{NMR} \\
\text { (Literature, } \delta \text { ) }\end{array}$ & $\begin{array}{c}{ }^{13} \mathrm{C}-\mathrm{NMR} \\
\text { (Predicted, } \delta \text { ) }\end{array}$ & Difference \\
\hline $\mathrm{C}_{1}$ & 38.7 & 39.3 & 0.5 \\
\hline $\mathrm{C}_{2}$ & 26.6 & 27.2 & 0.6 \\
\hline $\mathrm{C}_{3}$ & 89.0 & 89.6 & 0.6 \\
\hline $\mathrm{C}_{4}$ & 39.5 & 40.1 & 0.5 \\
\hline $\mathrm{C}_{5}$ & 55.8 & 56.6 & 0.8 \\
\hline $\mathrm{C}_{6}$ & 18.3 & 18.9 & 0.6 \\
\hline $\mathrm{C}_{7}$ & 33.4 & 34.0 & 0.6 \\
\hline $\mathrm{C}_{8}$ & 39.9 & 40.5 & 0.6 \\
\hline $\mathrm{C}_{9}$ & 47.1 & 47.6 & 0.5 \\
\hline $\mathrm{C}_{10}$ & 36.9 & 37.5 & 0.6 \\
\hline $\mathrm{C}_{11}$ & 23.7 & 24.3 & 0.6 \\
\hline $\mathrm{C}_{12}$ & 122.8 & 123.3 & 0.5 \\
\hline$C_{13}$ & 144.3 & 144.9 & 0.6 \\
\hline $\mathrm{C}_{14}$ & 42.0 & 42.6 & 0.6 \\
\hline $\mathrm{C}_{15}$ & 36.1 & 36.7 & 0.6 \\
\hline $\mathrm{C}_{16}$ & 74.0 & 74.6 & 0.6 \\
\hline $\mathrm{C}_{17}$ & 49.5 & 50.0 & 0.5 \\
\hline $\mathrm{C}_{18}$ & 41.2 & 41.7 & 0.5 \\
\hline $\mathrm{C}_{19}$ & 47.0 & 47.6 & 0.6 \\
\hline $\mathrm{C}_{20}$ & 30.9 & 31.5 & 0.6 \\
\hline $\mathrm{C}_{21}$ & 35.9 & 36.5 & 0.6 \\
\hline $\mathrm{C}_{22}$ & 32.1 & 32.6 & 0.5 \\
\hline $\mathrm{C}_{23}$ & 28.1 & 28.7 & 0.6 \\
\hline $\mathrm{C}_{24}$ & 16.9 & 17.5 & 0.6 \\
\hline $\mathrm{C}_{25}$ & 15.6 & 16.2 & 0.6 \\
\hline $\mathrm{C}_{26}$ & 17.5 & 18.1 & 0.6 \\
\hline $\mathrm{C}_{27}$ & 27.1 & 27.7 & 0.6 \\
\hline $\mathrm{C}_{28}$ & 175.9 & 176.5 & 0.6 \\
\hline $\mathrm{C}_{29}$ & 33.2 & 33.8 & 0.6 \\
\hline $\mathrm{C}_{30}$ & 24.7 & 25.3 & 0.6 \\
\hline
\end{tabular}

Fig. 1 Identification of LA from C. lanceolata. a Structure of LA (b) Mass spectra of precursor ion of LA and their fragmentation product ion were obtained in ESI negative-ion detection mode $\left([\mathrm{M}-\mathrm{H}]^{-}\right)$. In the mass spectrum, LA showed the ions to be at $\mathrm{m} / \mathrm{z} 1189.6$ (top panel). The tandem mass spectrum of the relative fragmentation product ions was monitored at $\mathrm{m} / \mathrm{z} 1189.6 \rightarrow 647.5$ for LA (bottom panel). The product ion at $\mathrm{m} / \mathrm{z}$ 647.5 was produced by loss of a tetrasaccharide unit (arabinose, rhamnose, and two xyloses). $\mathbf{c}$ For analysis of the correlation of the ${ }^{13} \mathrm{C}-\mathrm{NMR}$ values $(\delta, p p m)$ of $L A$, the ${ }^{13} \mathrm{C}$-NMR data of $L A$ were obtained from the literature. To validate the ${ }^{13} \mathrm{C}-\mathrm{NMR}$ data of $L A$, the chemical shifts of $L A$ were observed and compared with the literature data

The results showed that the reduced level of NO production in L-NAME-treated cells was recovered upon treatment with LA (Fig. 2c). Since $15 \mu$ M LA did not affect cell viability (above 85\%) and was effective for NO production in the cells, this concentration was used in further experiments.

\section{Effects of LA on the phosphorylation of eNOS and Akt}

After treatment with LA, as shown in Fig. 3a, compared with that in the control group, this treatment increased eNOS phosphorylation, whereas this phosphorylation was restrained by treatment with L-NAME. Moreover,
eNOS phosphorylation, which was reduced by treatment with L-NAME, was partially recovered by treatment with LA. Akt phosphorylation was analyzed using Western blotting. Figure $3 \mathrm{~b}$ shows that LA, but not L-NAME, also contributed to Akt phosphorylation.

\section{Effect of LA on stimulation of the PI3K/Akt/eNOS signaling pathway}

Western blotting was performed to investigate the protein levels of Akt, p-Akt, eNOS, and p-eNOS (Fig. 4). As shown in Fig. 4a, LA significantly increased p-eNOS and p-Akt inhibited by LY294002. Likewise, LA substantially 

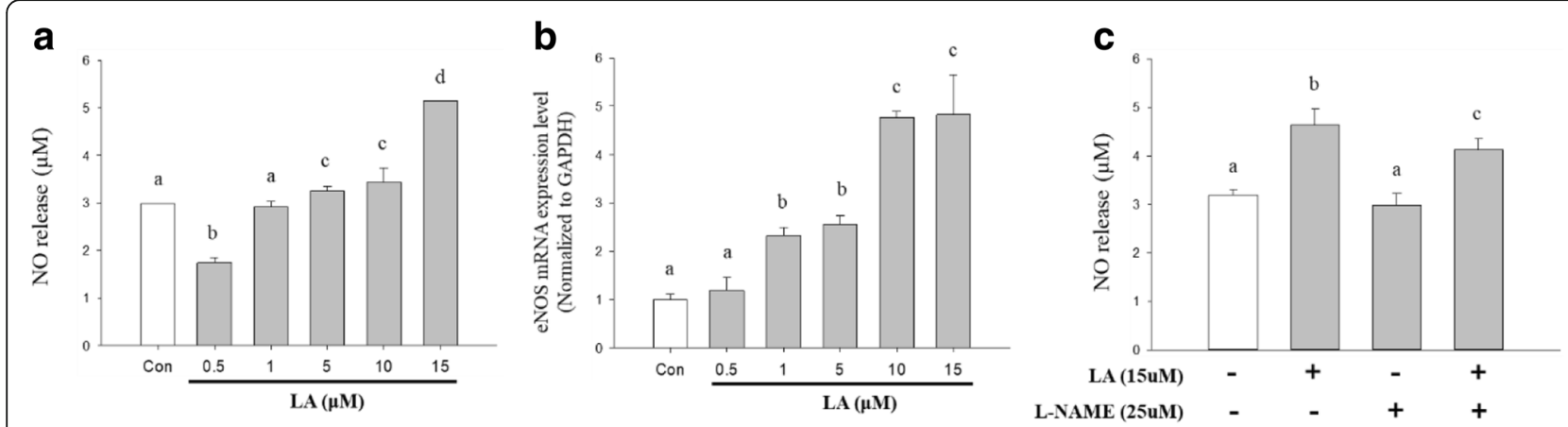

Fig. 2 The effects of LA on nitric oxide synthesis in HUVECs. a HUVECS were treated with various concentrations of $L A(0.5,1,5,10$, and $15 \mu M)$ for $24 \mathrm{~h}$, followed by the Griess assay. Con - non-treated negative control (b) The expression of eNOS mRNA levels in HUVECs, the cells were treated with various concentrations of $L A(0.5,1,5,10$, and $15 \mu M)$ for $24 \mathrm{~h}$, followed by the measurement of eNOS mRNA expression levels using qRT-PCR. These data are normalized by the mRNA expression levels of GAPDH. c Measurement of the activity of LA against the L-N(g)-nitro-Larginine methyl ester (L-NAME)-induced decrease of nitric oxide (NO) production. The cells were treated with $15 \mu \mathrm{M} L A$ for $24 \mathrm{~h}$, after which they were treated with $25 \mu \mathrm{M}$ L-NAME for $24 \mathrm{~h}$, followed by the Griess assay. Different letters indicate a statistically significant difference between each group at ${ }^{*} P<0.05$, as determined by Duncan's multiple-range test

improved and reversed p-eNOS and p-Akt blocked by A6730 (Fig. 4b). Moreover, LY294002 and A6730 can inhibit eNOS phosphorylation.

\section{Discussion}

The method using TLC developing solvent mixture of chloroform $/ \mathrm{MeOH} / \mathrm{H}_{2} \mathrm{O}$ (65:35:10) was very effective for screening those containing LA among fraction samples, after which the detection was easily confirmed with $10 \%$ sulfuric acid spray on TLC plate.
Many studies on the effect of saponin-rich C. lanceolata as a bioactive source for improving physical health have been performed [3, 4, 34-39]. These saponins are known to be particularly involved in the regulation of blood pressure or hypertension. The bioactivities of LA which is a saponin, isolated from C. lanceolata remain to be sufficiently elucidated [40]. In this study, NO synthesis with LA treatment in human umbilical vein endothelial cells, HUVECs was investigated. The HUVECs have been widely used as a laboratory in vitro model

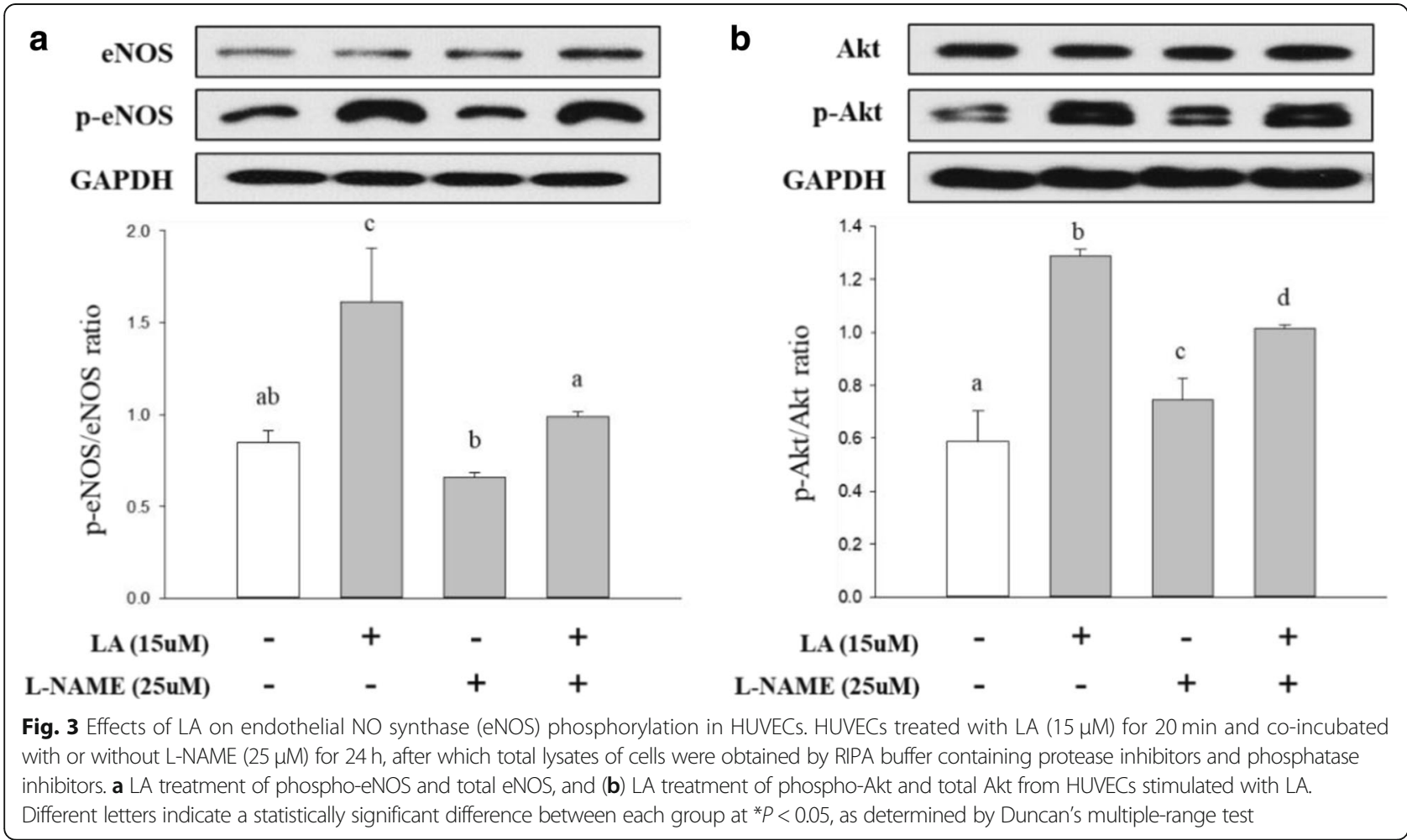



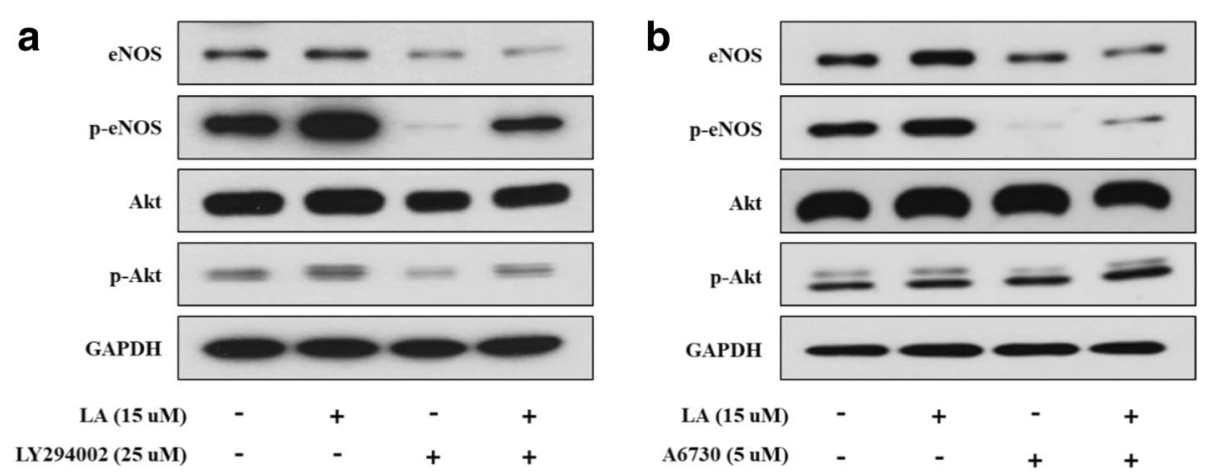

Fig. 4 Effects of LA on eNOS phosphorylation via the PI3KJAkt signaling pathway in HUVECs. HUVECs treated with LA (15 $\mu \mathrm{M})$ for 20 min and coincubated with or without PI3K inhibitor (LY294002, $25 \mu \mathrm{M})$ and an Akt phosphorylation inhibitor (A6730, $5 \mu \mathrm{M})$ for $15 \mathrm{~h}$. a Phosphorylation of eNOS and Akt was inhibited by LY294002; however, it was enhanced by treatment with LA, and (b) A6730 also suppressed the phosphorylation of eNOS and Akt, but their phosphorylation was improved by LA treatment

system for studying endothelial cell functions and responses to stress [41]. We made efforts to identify LA from the ethanol extract of $C$. lanceolata by several instrumental approaches and to evaluate its effect on $\mathrm{NO}$ production via eNOS activation.

Endothelial NOS is one of four isoforms of NOS, which also include iNOS, nNOS, and bNOS [42, 43]. NO synthesis, which is regulated by eNOS in endothelial cells, is closely connected to vasodilation related to blood pressure [44]. It has been reported that NO released by HUVECs activates sGC, which is a NO receptor in SMC, thereby converting GTP to cGMP, and this activation can lead to vascular relaxation $[24,45]$. To elucidate the effect of LA on the phosphorylation of eNOS, which is a protein involved in NO production, HUVECs were treated with LA $(15 \mu \mathrm{M})$ and L-NAME $(25 \mu \mathrm{M})$. Our results showed that NO production was efficiently improved by treatment with LA in a dose-dependent manner. Furthermore, as the effect of LA against L-NAME-inhibited NO production, the LA treatment resulted in extensive recovery of the NO production suppressed by the eNOS inhibitor, L-NAME, compared with that in the control group. In addition, this treatment increased the level of eNOS mRNA in a dose-dependent manner. These results suggested that LA is an inducer of NO synthesis via eNOS mRNA expression. The phospho-eNOS in the vascular endothelium aggressively induces NO generation, leading to the regulation of vascular tone and cellular proliferation [46]. eNOS phosphorylation progressed remarkably compared with that in the untreated group and the group treated with the eNOS inhibitor, L-NAME (Fig. 3). Furthermore, protein kinase $B(\mathrm{PKB} / \mathrm{Akt})$ is well known to elevate eNOS phosphorylation [47]. As determination of eNOS activation, LA significantly increased and recovered p-eNOS and p-Akt levels although PI3K/Akt/eNOS signaling pathway inhibition was induced by LY294002 and A6730 (Fig. 4). These results demonstrated that Akt phosphorylation is involved in eNOS phosphorylation related to
$\mathrm{NO}$ production and that LA is involved in activating the PI3K/Akt/eNOS signaling pathway. On the other hand, it would be more interesting to study further structure-activity relationship of LA.

\section{Conclusions}

This study demonstrated that LA, a saponin from C. lanceolate, enhances endothelial cell function, such as NO synthesis, via eNOS activation in the PI3K/Akt/eNOS signaling pathway, suggesting the value of using LA as a component of functional foods and natural pharmaceuticals.

\section{Additional files}

Additional file 1: Figure S1. Determination of lancemaside $A(L A)$ from C. lanceolata. (a) Scheme showing the isolation of LA from C. lanceolata. (b) Thin-layer chromatography, TLC analysis was performed to identify LA in the $n$-butanol-soluble portion (top panel). Open column was packed with the silica gel fractions (3-7) eluted by a dichloromethane-methanol solvent gradient (middle panel) and HPLC fractions (27-29) were separated by a linear gradient of solvent mixtures of $0.05 \%$ trifluoroacetic acid in $\mathrm{H}_{2} \mathrm{O}$ (TFA, solvent A) and acetonitrile (solvent B) (bottom panel) (DOCX $399 \mathrm{~kb}$ )

Additional file 2: Table S1. Liquid chromatography-tandem mass spectrometry (LC-MS/MS) conditions for the determination of lancemaside A (LA) (A) and summary of MS \& MS/MS chromatogram spectrum in negative ion mode of $L A(B)(D O C X 25 \mathrm{~kb})$

\section{Abbreviations}

ACN: Acetonitrile; bNOS: bacterial NO synthase; cGMP: cyclic guanosine monophosphate; CREB: CAMP responsive element binding protein; DCM: Dichloromethane; ECL: Enhanced chemiluminescence; EGM2: Endothelial growth medium-2; eNOS: endothelial NOS; FAK: Focal adhesion kinase; FBS: Fetal bovine serum; GTP: Guanosine triphosphate; HRP: Horseradish peroxidase; iNOS: inducible NOS; LA: Lancemaside A; LNAME: L-N(G)-nitro-L-arginine methyl ester; NMR: Nuclear magnetic resonance; nNOS: neuronal NOS; NO: Nitric oxide; PKB: Protein kinase B; SBP: Systolic blood pressure; SGC: soluble guanylyl cyclase; SMC: Smooth muscle cells; TFA: Trifluoroacetic acid; TLC: Thin-layer chromatography 


\section{Acknowledgements}

The authors thank the Korea University-CJ Food Safety Center (Seoul, South Korea) for providing equipment and facilities, and School of Life Science and Biotechnology for BK21 PLUS, Korea University for technical support.

\section{Funding}

This research was supported by a grant from the National Research Foundation of Korea Forest Service (KFS) (R1605812). The funding body did not play a role in the study design, performance, data collection and analysis, decision to publish, or preparation/writing of the manuscript.

\section{Availability of data and materials}

All data and analyses in the current study are available from the corresponding author upon reasonable request.

\section{Authors' contributions}

LYS, KHE, SGH, and LKW Participated in research design. KHE, SGH, and LKW Contributed new regents or analytical tools. LYS, KHE, and LKW Performed data analysis. LYS, KHE, SGH, and LKW Wrote or contributed to the writing of the manuscript. All authors read and approved the final manuscript.

\section{Ethics approval and consent to participate}

Not applicable.

\section{Consent for publication}

Not applicable.

\section{Competing interests}

The authors declare that they have no competing interests.

\section{Publisher's Note}

Springer Nature remains neutral with regard to jurisdictional claims in published maps and institutional affiliations.

\section{Author details}

'Department of Biotechnology, College of Life Science and Biotechnology, Korea University, 212 CJ Food Safety Hall, Sungbuk-Gu, Anam-Ro 145, Seoul 02841, South Korea. ${ }^{2}$ Institute of Biomedical Science and Food Safety, Korea University, Seoul 02841, South Korea. ${ }^{3}$ Department of Basic Nursing Science, College of Nursing, Korea University, Seoul 02841, South Korea.

Received: 12 November 2018 Accepted: 30 April 2019

Published online: 24 May 2019

\section{References}

1. Lee YG, Kim JY, Lee JY, Byeon SE, Hong EK, Lee J, et al. Regulatory effects of Codonopsis lanceolata on macrophage-mediated immune responses. J Ethnopharmacol. 2007:112:180-8.

2. Lee J-H. Immunostimulative effect of hot-water extract from Codonopsis lanceolata on lymphocyte and clonal macrophage. Korean J Food Sci Technol. 2002;34:732-6.

3. Cho K, Kim S-J, Park S-H, Kim S, Park T. Protective effect of Codonopsis lanceolata root extract against alcoholic fatty liver in the rat. J Med Food. 2009;12(6):1293-301.

4. Kim MH, Lee J, Yoo DS, Lee YG, Byeon SE, Hong EK, et al. Protective effect of stress-induced liver damage by saponin fraction from Codonopsis lanceolata. Arch Pharm Res. 2009;32:1441-6.

5. Choi H-K, Won E-K, Jang YP, Choung S-Y. Antiobesity effect of Codonopsis lanceolata in high-calorie/high-fat-diet-induced obese rats. Evid-Based Compl Alt. 2013;2013.

6. Han C, Li L, Piao K, Shen Y, Piao Y. Experimental study on anti-oxygen and promoting intelligence development of Codonopsis lanceolata in old mice. J Chinese Med Mater. 1999;22:136-8.

7. Weon JB, Lee B, Yun B-R, Lee J, Lee HY, Park D-S, et al. Memory enhancing effect of Codonopsis lanceolata by high hydrostatic pressure process and fermentation. Korean J Pharmacogn. 2013;44:41-6.

8. Cho Y, Kim S, Yoon H, Hong S, Ko H, Park E, et al. Anti-tumor effects of Codonopsis lanceolata extracts on human lung and ovarian cancer. Food Eng Prog. 2011.

9. Ichikawa M, Ohta S, Komoto N, Ushijima M, Kodera Y, Hayama M, et al. Simultaneous determination of seven saponins in the roots of Codonopsis lanceolata by liquid chromatography-mass spectrometry. J Nat Med. 2009; 63(1):52-7.

10. Simeonova R, Vitcheva V, Kondeva-Burdina M, Krasteva I, Nikolov S, Mitcheva M. Effect of purified saponin mixture from Astragalus corniculatus on enzyme-and non-enzyme-induced lipid peroxidation in liver microsomes from spontaneously hypertensive rats and normotensive rats. Phytomedicine. 2010;17(5):346-9.

11. Pan C, Huo Y, An X, Singh G, Chen M, Yang Z, et al. Panax notoginseng and its components decreased hypertension via stimulation of endothelial-dependent vessel dilatation. Curr Vasc Pharmacol. 2012;56(3):150-8.

12. Hiwatashi K, Shirakawa H, Hori K, Yoshiki Y, Suzuki N, Hokari M, et al. Reduction of blood pressure by soybean saponins, renin inhibitors from soybean, in spontaneously hypertensive rats. Biosci Biotechnol Biochem. 2010;74(11):2310-2.

13. Han AY, Lee YS, Kwon S, Lee HS, Lee KW, Seol GH. Codonopsis lanceolata extract prevents hypertension in rats. Phytomedicine. 2018;39:119-24.

14. Kim E, Yang WS, Kim JH, Park JG, Kim HG, Ko J, et al. Lancemaside A from Codonopsis lanceolata modulates the inflammatory responses mediated by monocytes and macrophages. Mediat Inflamm. 2014;2014.

15. Joh E-H, Lee I-A, Han S-J, Chae S, Kim D-H. Lancemaside A ameliorates colitis by inhibiting NF-KB activation in TNBS-induced colitis mice. Int J Color Dis. 2010;25(5):545-51.

16. Jeong Y-H, Jung J-S, Van Le TK, Kim D-H, Kim H-S. Lancemaside A inhibits microglial activation via modulation of JNK signaling pathway. Biochem Biophys Res Commun. 2013;431:369-75.

17. Li X, Li J, Li Z, Sang Y, Niu Y, Zhang Q, et al. Fucoidan from Undaria pinnatifida prevents vascular dysfunction through PI3K/Akt/eNOSdependent mechanisms in the L-NAME-induced hypertensive rat model. Food Funct. 2016;7:2398-408.

18. Kobayashi N, Ohno T, Yoshida K, Fukushima H, Mamada Y, Nomura M, et al. Cardioprotective mechanism of telmisartan via PPAR-gamma-eNOS pathway in dahl salt-sensitive hypertensive rats. Am J Hypertens. 2008; 21:576-81.

19. Urano T, Ito Y, Akao M, Sawa T, Miyata K, Tabata M, et al. Angiopoietinrelated growth factor enhances blood flow via activation of the ERK1/2eNOS-NO pathway in a mouse hind-limb ischemia model. Arterioscler Thromb Vasc Biol. 2008;28(5):827-34.

20. Lee SH, Lee YJ, Song CH, Ahn YK, Han HJ. Role of FAK phosphorylation in hypoxia-induced hMSCS migration: involvement of VEGF as well as MAPKS and eNOS pathways. Am J Physiol Cell Physiol. 2010;298:C847-56.

21. Shiojima I, Walsh K. Role of Akt signaling in vascular homeostasis and angiogenesis. Circ Res. 2002;90:1243-50.

22. Lin MI, Fulton D, Babbitt R, Fleming I, Busse R, Pritchard KA, et al. Phosphorylation of threonine 497 in endothelial nitric-oxide synthase coordinates the coupling of L-arginine metabolism to efficient nitric oxide production. J Biol Chem. 2003;278:44719-26.

23. Beleslin-Cokic BB, Cokic VP, Yu X, Weksler BB, Schechter AN, Noguchi CT. Erythropoietin and hypoxia stimulate erythropoietin receptor and nitric oxide production by endothelial cells. Blood. 2004;104:2073-80.

24. Xia T, Guan W, Fu J, Zou X, Han Y, Chen C, et al. Tirofiban induces vasorelaxation of the coronary artery via an endothelium-dependent NOcGMP signaling by activating the PI3K/Akt/eNOS pathway. Biochem Biophys Res Commun. 2016;474:599-605.

25. Liu D-H, Chen Y-M, Liu Y, Hao B-S, Zhou B, Wu L, et al. Ginsenoside Rb1 reverses $\mathrm{H} 2 \mathrm{O}$-induced senescence in human umbilical endothelial cells: involvement of eNOS pathway. J Cardiovasc Pharmacol Ther. 2012;59:222-30.

26. Leung KW, Cheng Y-K, Mak NK, Chan KK, David Fan T, Wong RN. Signaling pathway of ginsenoside-Rg1 leading to nitric oxide production in endothelial cells. FEBS Lett. 2006;580:3211-6.

27. Ushijima M, Komoto N, Sugizono Y, Mizuno I, Sumihiro M, Ichikawa M, et al. Triterpene glycosides from the roots of Codonopsis lanceolata. Chem Pharm Bull. 2008 Mar;56:308-14.

28. Du YE, Lee JS, Kim HM, Ahn J-H, Jung IH, Ryu JH, Choi, J-H, Jang DS Chemical constituents of the roots of Codonopsis lanceolata. Arch Pharm Res. 2018:41:1082-1091.

29. Li J-P, Liang Z-M, Yuan Z. Triterpenoid saponins and anti-inflammatory activity of Codonopsis lanceolata. Pharmazie. 2007;62:463-6.

30. Hyam SR, Jang S-E, Jeong J-J, Joh E-H, Hand MJ, Kim D-H. Echinocystic acid, a metabolite of lancemaside A, inhibits TNBS-induced colitis in mice. Int Immunopharmacol. 2013;15:433-41. 
31. Komoto N, Ichikawa M, Ohta S, Nakano D, Nishihama T, Ushijima M, et al. Murine metabolism and absorption of lancemaside $\mathrm{A}$, an active compound in the roots of Codonopsis lanceolata. J Nat Med. 2010;64:321-9.

32. Ichikawa M, Ohta S, Komoto N, Ushijima M, Kodera Y, Hayama M, et al. Rapid identification of triterpenoid saponins in the roots of Codonopsis lanceolata by liquid chromatography-mass spectrometry. J Nat Med. 2008; 62:423-9.

33. Shirota O, Nagamatsu K, Sekita S, Komoto N, Kuroyanagi M, Ichikawa M, Ohta S, Ushijima M. Preparative separation of the saponin lancemaside A from Condonopsis lanceolata by centrifugal partition chromatography. Phytochem Anal. 2008:19:403-10.

34. Han E, Cho S. Effect of Codonopsis lanceolata water extract on the activities of antioxidative enzymes in carbon tetracholoride treated rats. J Korean Soc Food Sci Nutr. 1997;26:1181-6.

35. Lee K-W, Jung H-J, Park H-J, Kim D-G, Lee J-Y, Lee K-T. Beta-D-xylopyranosyl$(1 \rightarrow 3)$ - $\beta$-D-glucuronopyranosyl echinocystic acid isolated from the roots of Codonopsis lanceolata induces caspase-dependent apoptosis in human acute promyelocytic leukemia HL-60 cells. Biol Pharm Bull. 2005;28:854-9.

36. Xu L-P, Wang H, Yuan Z. Triterpenoid saponins with anti-inflammatory activity from Codonopsis lanceolata. Planta Med. 2008;74:1412-5.

37. Wang L, Xu ML, Hu JH, Rasmussen SK, Wang M-H. Codonopsis lanceolata extract induces G0/G1 arrest and apoptosis in human colon tumor HT-29 cells-involvement of ROS generation and polyamine depletion. Food Chem Toxicol. 2011;49:149-54.

38. Byeon SE, Choi WS, Hong EK, Lee J, Rhee MH, Park H-J, et al. Inhibitory effect of saponin fraction from Codonopsis lanceolata on immune cellmediated inflammatory responses. Arch Pharm Res. 2009;32:813-22.

39. Lee K-T, Choi J, Jung W-T, Nam J-H, Jung H-J, Park H-J. Structure of a new echinocystic acid bisdesmoside isolated from Codonopsis lanceolata roots and the cytotoxic activity of prosapogenins. J Agric Food Chem. 2002;50: 4190-3.

40. Joh EH, Kim DH. Lancemaside A inhibits lipopolysaccharide-induced inflammation by targeting LPS/TLR4 complex. J Cell Biochem. 2010;111:865-71.

41. Park H-J, Zhang Y, Georgescu SP, Johnson KL, Kong D, Galper JB. Human umbilical vein endothelial cells and human dermal microvascular endothelial cells offer new insights into the relationship between lipid metabolism and angiogenesis. Stem Cell Rev. 2006;2:93-101.

42. Knowles RG, Moncada S. Nitric oxide synthases in mammals. Biochem J. 1994;298:249-58.

43. Gusarov I, Shatalin K, Starodubtseva M, Nudler E. Endogenous nitric oxide protects bacteria against a wide spectrum of antibiotics. Science. 2009;325: $1380-4$.

44. Mukai Y, Sato S. Polyphenol-containing azuki bean (Vigna angularis) extract attenuates blood pressure elevation and modulates nitric oxide synthase and caveolin-1 expressions in rats with hypertension. Nutr Metab Cardiovasc Dis. 2009;19:491-7.

45. Huang PL, Huang Z, Mashimo H, Bloch KD. Hypertension in mice lacking the gene for endothelial nitric oxide synthase. Nature. 1995;377:239-42.

46. Förstermann U, Münzel T. Endothelial nitric oxide synthase in vascular disease. Circulation. 2006:113(13):1708-14.

47. Taguchi K, Matsumoto T, Kamata K, Kobayashi T. Akt/eNOS pathway activation in endothelium-dependent relaxation is preserved in aortas from female, but not from male, type 2 diabetic mice. Pharmacol Res. 2012;65: $56-65$.

\section{Ready to submit your research? Choose BMC and benefit from:}

- fast, convenient online submission

- thorough peer review by experienced researchers in your field

- rapid publication on acceptance

- support for research data, including large and complex data types

- gold Open Access which fosters wider collaboration and increased citations

- maximum visibility for your research: over $100 \mathrm{M}$ website views per year

At BMC, research is always in progress.

Learn more biomedcentral.com/submissions 